\title{
La Iglesia Católica frente a la política sexual: la configuración de una ciudadanía religiosa*
}

\author{
Juan Marco Vaggione**
}

\section{Resumen}

El debate por ampliar las fronteras de la ciudadanía sexual impulsado por los movimientos feministas y por la diversidad sexual dio lugar (paradójicamente) a la configuración de una ciudadanía religiosa. El principal propósito de este artículo es analizar esta configuración buscando comprender la política del activismo católico conservador en las democracias contemporáneas. En particular se proponen tres dimensiones de la ciudadanía religiosa: el trazado de fronteras identitarias, la movilización de creencias y el reconocimiento de derechos religiosos. Cada una de estas dimensiones iluminan aspectos distintos (aunque interconectados) de la política de la Iglesia Católica en reacción a los impactos, reales e imaginarios, del reconocimiento de derechos sexuales y reproductivos.

Palabras clave: Ciudadania Religiosa, Derechos Sexuales y Reproductivos, Politica Sexual, Iglesia Catolica, Activismo Catolico Conservador.

\footnotetext{
Recebido para publicação em 11 de janeiro de 2017, aceito em 8 de maio de 2017.

** Profesor de la Universidad Nacional de Córdoba e Investigador del Consejo Nacional de Investigaciones Científicas y Técnicas (CONICET). El autor agradece las lecturas y comentarios de lxs evaluadores $y$ editores. juanvaggione@gmail.com
} 
The Catholic Church Faces Sexual Politics: The Configuration of a Religious Citizenship

\begin{abstract}
The expansion of the frontiers of sexual citizenship driven by feminist and sexual diversity movements gave rise (paradoxically) to the configuration of a religious citizenship. The main purpose of this article is to analyze this configuration in order to understand the politics of conservative Catholic activism in contemporary democracies. In particular, three dimensions of religious citizenship are proposed: the redrawing of identity borders, the mobilization of beliefs and the recognition of religious rights. Each of these dimension illuminates different (though interconnected) aspects of the Catholic Church policy in reaction to the real and imagined challenges imposed by the recognition of sexual and reproductive rights.
\end{abstract}

Keywords: Religious Citizenship, Sexual and Reproductive Rights, Sexual Politics, Conservative Religious Activism. 


\section{Introducción}

En abril del 2008 Benedicto XVI durante su visita a las Naciones Unidas afirmó que el derecho natural es el basamento de los derechos humanos y consideró inconcebible que "los creyentes tengan que suprimir una parte de sí mismos -su fe-para ser ciudadanos activos" (Benedicto XVI, 2008). Frente a posturas que defienden la necesidad de excluir las creencias religiosas del ejercicio de la ciudadanía, el pontífice reforzó en su discurso la centralidad de las mismas. En otro pasaje sostuvo que "Los derechos asociados con la religión necesitan protección sobre todo si se los considera en conflicto con la ideología secular predominante o con posiciones de una mayoría religiosa de naturaleza exclusiva". El Papa volvió a considerar la existencia del secularismo como una ideología que amenaza la libertad de creencias en las sociedades contemporáneas. Finalmente sostuvo que los derechos humanos tienen como una de sus principales funciones la protección de distintos derechos asociados a la religión para que "los creyentes contribuyan (a) la construcción del orden social".

Los extractos citados condensan uno de los aspectos del giro conservador católico que analiza este artículo: la configuración de una ciudadanía religiosa. El impacto de los movimientos feministas y por la diversidad sexual en la política contemporánea implicó, entre otras cuestiones, una intensificación en la defensa de derechos vinculados al libre ejercicio y expresión de lo religioso. Tanto en las arenas transnacionales como en las nacionales la Iglesia Católica y sectores aliados ${ }^{1}$ instrumentan estrategias y circulan argumentaciones en defensa de las creencias religiosas como forma de resistir al proceso de sexualización de la ciudadanía. Este giro conservador no se manifiesta en el contenido moral de lo defendido (la moral sexual de la Iglesia se ha

\footnotetext{
1 Como se ha analizado en otros artículos, el activismo católico conservador se compone por una red de actores y organizaciones tanto religiosos como seculares (Vaggione, 2005 y 2013).
} 
mantenido por siglos) sino en las renovadas estrategias con que este contenido se defiende. Al margen de sus (no pocas) diferencias, los últimos tres Papas tienen en común la defensa innegociable del derecho natural como basamento de los órdenes legales nacionales $e$ internacionales en temáticas vinculadas a la sexualidad.

El principal propósito de este artículo es analizar la consolidación de un proyecto de ciudadanía religiosa para comprender (al menos parcialmente) la política del activismo católico conservador en las democracias contemporáneas. En distintos trabajos hemos propuesto el concepto de "secularismo estratégico" para captar diversas manifestaciones de este activismo en la resistencia a los Derechos Sexuales y Reproductivos (DDSSRR) (Vaggione, 2005, 2013). Frente al debate público sobre las formas de regular la sexualidad, la Iglesia intensificó el uso de argumentaciones seculares para potenciar su impacto en la construcción del derecho. El foco de este artículo es un proceso diferente, aunque complementario: las formas en que el activismo católico moviliza y protege las creencias religiosas en oposición a los DDSSRR. Si los trabajos previos enfatizan el desplazamiento hacia lo secular, en este se considera el uso estratégico de las creencias religiosas para impactar en la construcción del derecho secular. Tanto el concepto de secularismo estratégico como el de ciudadanía religiosa, tienen como propósito captar las articulaciones políticas de lo religioso que emergen como respuesta al impacto de los movimientos feministas y por la diversidad sexual en las democracias contemporáneas.

El concepto de ciudadanía religiosa permite identificar distintas dimensiones que colocan en tensión la política sexual contemporánea. En particular se proponen tres facetas del concepto para profundizar el proceso de configuración del ciudadano en tanto creyente: el trazado de fronteras identitarias, la movilización de creencias y el reconocimiento de derechos religiosos. Cada una de estas facetas ilumina aspectos distintos (aunque interconectados) de la política de la Iglesia Católica, tanto global como nacional, en reacción a los impactos de los 
movimientos feministas y por la diversidad sexual. Para la observación y el análisis de las mismas se consideran dos fuentes de datos. Por un lado, se observan documentos de la Iglesia Católica, particularmente del Vaticano, donde se delinean los principales posicionamientos y rearticulaciones frente a los DDSSRR. Por otro lado, se presentan algunos resultados de investigaciones llevadas a cabo en Argentina por integrantes del Programa en Derechos Sexuales y Reproductivos bajo mi dirección. ${ }^{2}$ Estas investigaciones analizan las principales estrategias de la Iglesia Católica y sectores aliados para impactar sobre los procesos de sanción e interpretación del derecho. Sin desconocer las especificidades de los distintos contextos, la consolidación de la ciudadanía religiosa (y sus dimensiones) son parte de un proyecto que trasciende al estado-nación.

\section{La ciudadanía religiosa: identidad, participación y derechos}

El análisis de T.H. Marshall (1950) en Inglaterra, es un aporte clásico en los debates sobre la ciudadanía. Según el autor, el concepto de ciudadanía tiene tres componentes principales (civil, político y social) y cada uno de ellos da lugar, en distintos momentos históricos, al reconocimiento de un conjunto de derechos. Su propuesta ha sido criticada desde distintos puntos de vista que evidenciaron, entre otras, dos limitaciones particulares. ${ }^{3}$ Por un lado, la distancia entre los derechos ciudadanos como discurso igualitario y las desigualdades materiales existentes (particularmente las de clase). Estas dificultan, o incluso imposibilitan, el ejercicio de los derechos civiles, políticos y sociales. Y por otro lado, la importancia de los movimientos sociales para comprender la ampliación de los derechos

2 Este Programa está radicado en la Facultad de Derecho de la Universidad de Córdoba.

${ }^{3}$ Existe una amplia bibliografía sobre estos debates críticos a T.H. Marshall que exceden el propósito de este artículo. Se destacan por sus trabajos pioneros y ya clásicos Tom Bottomore (1992), Bryan Turner (1990) y Nancy Fraser y Linda Gordon (1992). 
ciudadanos. Lejos de ser una concesión estatal, estos derechos son el resultado de luchas y conflictos que logran ser incluidos en la arena política.

Las diferentes críticas han sofisticado la formulación clásica de Marshall dando lugar, entre otras cuestiones, a abordajes más complejos y multidimensionales. Un momento teórico y político, clave de estas reformulaciones, es el impacto de los movimientos feministas y por la diversidad sexual. Estos movimientos visibilizan las formas en que la ciudadanía se asienta sobre un cuerpo hegemónico (masculino y heterosexual) marginando las identidades y prácticas que se alejan del mismo. Debido a su identidad de género, su orientación sexual o sus prácticas sexuales, distintas personas ven vulnerado el ejercicio de sus derechos civiles, políticos o sociales (Lister, 2002). Bajo la formalización de la ciudadanía, se invisibilizan las distintas barreras (materiales y simbólicas) que impiden a ciertos individuos acceder a los mismos. Por ejemplo, las mujeres estuvieron excluidas por décadas de los derechos políticos, las personas trans privadas de los laborales y las parejas del mismo sexo de los civiles.

Pero estos movimientos van más allá y ponen en agenda una serie de derechos que amplían las fronteras ciudadanas. A través de reformas legales y casos jurisprudenciales se pone en circulación un paradigma alternativo (no libre de tensiones y limitaciones ${ }^{4}$ ) sobre la articulación entre estado y sexualidad que, entre otros efectos, dan lugar a un régimen secular de la sexualidad con una regulación moral que les es propia (Carrara, 2015:326). La demanda por los DDSSRR politiza el placer y la ética sexual y permite rediscutir las fronteras morales sobre las que se asienta la ciudadanía. Tales consignas se movilizan no sólo por desmantelar las barreras que impiden a ciertas personas gozar de derechos existentes, sino también por el reconocimiento de "nuevos" derechos que amplíen los debates sobre la ciudadanía

${ }^{4}$ Existen distintas críticas a los DDSSRR en general y a la sexualización de la ciudadanía en particular debido a las potenciales consecuencias asimilacionistas y/o neo-colonialistas (entre otras). 
para incluir la sexualidad. Conceptos como ciudadanía sexual (Lister, 1997) o ciudadanía íntima (Plummer, 2003) marcan la incorporación de las prácticas e identidades sexo-genéricas a los debates sobre las fronteras morales de la ciudadanía.

Este corrimiento de las fronteras morales implica de manera directa una crítica a la influencia de las religiones sobre la política. Des-moralizar la ciudadanía e incrementar el pluralismo ético requiere no sólo visibilizar el impacto de las principales religiones sino también desmontar estas influencias de la construcción de la ciudadanía. A pesar de su presencia (determinante en muchas circunstancias) lo religioso (al igual que lo sexual) quedó desplazado de las principales discusiones sobre los derechos ciudadanos. Si bien se garantizaron algunos derechos básicos (vinculados a la libertad religiosa y de conciencia), las creencias religiosas tendieron a excluirse de los debates sobre la ciudadanía. Esto se debe a que la ciudadanía, en tanto proyecto normativo, estuvo fuertemente influenciado por la teoría de la secularización, lo que implicó, entre otras cuestiones, la desatención a los aspectos religiosos como parte de la construcción ciudadana (Calhoun, 2011). La distinción entre el ciudadano y el creyente se corresponde con la clásica distinción entre lo público y lo privado, limitando el ámbito de las creencias religiosas a este último. La fuerte impronta secularista de las críticas de los movimientos feministas y por la diversidad sexual, a pesar de replantear diversos aspectos de la ciudadanía, reforzaron la exclusión de las creencias religiosas como dimensión legítima. No deja de ser llamativo que el corset de lo privado que estos movimientos tuvieron que desmontar para politizar la sexualidad, se refuerce (en general) para contener lo religioso por fuera de la ciudadanía.

En los últimos años, la insuficiente teorización sobre los aspectos religiosos de la ciudadanía comenzó a ser abordada. La presencia pública de las principales religiones y las limitaciones de la teoría de la secularización llevaron a un replanteo de las principales agendas académicas respecto a los marcos analíticos y 
normativos para captar la articulación entre religión y política. ${ }^{5}$ Dentro de este replanteo algunos estudios se volcaron a repensar la relación entre ciudadanía y creencias religiosas. Se produce entonces una revisión, muchas veces superadora, de la impronta secularista o laica de la mayoría de los debates sobre la ciudadanía (Calhoun, 2011). Parte de esta revisión comienza a utilizar el concepto de ciudadanía religiosa para captar aspectos otrora minimizados o excluidos. Al concepto de ciudadanía se le fueron adosando una serie de adjetivos (tales como global, racial o multicultural) para visibilizar sus limitaciones y proponer nuevos abordajes. Precisamente el concepto de ciudadanía religiosa señala una dimensión poco reflexionada a la vez que abre a nuevos debates y áreas de indagación.

Pueden identificarse tres abordajes principales en la utilización del concepto de ciudadanía religiosa (Nyhagen, 2015). Estos abordajes se distinguen por motivos analíticos, ya que la mayoría de los estudios los mixturan e integran. En primer lugar, algunos estudios privilegian una mirada formalista prestando atención a los aspectos legales que vinculan los debates sobre ciudadanía y las creencias religiosas (Nyhagen, 2015; Permoser y Rosberberg 2009). Este tipo de estudios pone el acento sobre el estado $\mathrm{u}$ organismos internacionales y su papel en garantizar los derechos religiosos de los ciudadanos. En segundo lugar, existen estudios que analizan las maneras en que los individuos entienden y negocian la ciudadanía con su experiencia religiosa (Hudson, 2003; Yuval-Davis, 1999). Estos estudios, en general con un abordaje de corte sociológico o antropológico, tienden a considerar a la ciudadanía como parte de un proceso de identidades múltiples que no se reducen a los límites del estadonación. Finalmente, otro tipo de debate que vincula la ciudadanía y lo religioso se da en un plano normativo e interroga sobre el derecho de los ciudadanos (o no) a utilizar argumentaciones y razones religiosas durante los debates públicos. Desde este

5 Si bien la bibliografía sobre estos debates es extensa, los aportes de Casanova (1994) sobre la temática marcan un punto de inflexión. 
abordaje se debate la legitimidad de exigir a los ciudadanos religiosos que utilicen exclusivamente razones seculares al momento de participar públicamente ${ }^{6}$.

Aunque los estudios que utilizan el concepto de ciudadanía religiosa son escasos, consideramos que el mismo es un instrumento heurístico relevante para comprender la política sexual contemporánea. Siguiendo aquellos análisis que identifican múltiples facetas (o usos) de concepto de ciudadanía (Leydet, 2014, Cohen 1999; Kymlicka; Norman 2000), se presentan a continuación tres dimensiones interconectadas de las formas en que la Iglesia Católica politiza las creencias religiosas como constitutiva de la ciudadanía.

\section{a. La ciudadanía como identidad: el trazado de fronteras culturales}

Una de las dimensiones del concepto de ciudadanía es la membresía, el formar parte, de una comunidad política. En general, esta dimensión solía limitarse a la incorporación (la pertenencia) al modelo de nación como proyecto de la modernidad. Sin embargo, diversas críticas han posibilitado una mayor complejización de los aspectos culturales e identitarios de la pertenencia comunitaria de los ciudadanos. En particular, el impacto de los denominados "nuevos movimientos sociales", entre los que se ubican los feminismos y movimientos por la diversidad sexual, pusieron en debate la importancia del reconocimiento, la identidad o las injusticias culturales tanto en la movilización como en las políticas de pertenencia. ${ }^{7}$ Este desplazamiento (a veces referido como el paso de una política de clase a una política de identidades) evidenció que la ciudadanía es, también, un proyecto identitario y que el trazado de sus

${ }^{6}$ Los procesos migratorios de población musulmana a Europa son un ejemplo en el cual se evidencian cómo ciertas matrices occidentales y seculares de la ciudadanía potencian la desigualdad de poblaciones vulnerables.

7 Algunos de los conceptos utilizados para referir a estos aspectos son reconocimiento (Taylor, 1992); injusticias culturales (Fraser, 1995) o humillación (Avisahi, 1996). 
fronteras implica, inevitablemente, una política compleja de inclusión y exclusión (Sabsay, 2011).

La consideración de los aspectos identitarios permite, entre otras cosas, repensar críticamente las fronteras de membresía ciudadana. Sin desconocer la importancia de la nación como proyecto, la ciudadanía es un fenómeno con 'múltiple capas' (o 'multi-layered' en términos de Yural-Davis 2007) que se caracteriza por la pertenencia simultánea a distintas comunidades políticas. Entre estas pertenencias las comunidades religiosas han sido probablemente las más resistentes y no dejaron de tener importantes impactos sociopolíticos en diferentes contextos. Según Yural-Davis la globalización neoliberal ha producido la emergencia o el fortalecimiento de formas diversas de pertenencia interseccional entre las que se destacan las comunidades religiosas (Yural-Davis, 2011). No sólo las principales religiones son proveedoras de servicios básicos 8 sino que también generan matrices de pertenencia comunitaria y, eventualmente, política que coexisten con/en la nación. En contra de la mayoría de los pronósticos, no sólo lo religioso sobrevivió a la Modernidad sino que incluso se fortaleció como una comunidad de pertenencia cultural y política (Casanova, 1994).

En la mayoría de los países de América Latina, el impacto histórico y cultural de la Iglesia Católica produjo modelos de pertenencia nacional demarcados por los principios católicos. La Iglesia tuvo un papel determinante en la construcción de las identidades y proyectos nacionales que acompañaron la construcción de los estados en la región. Esta influencia se dio con particular agudeza en relación con el orden sexual ya que la Iglesia delimitaba el contenido de la familia nacional como reflejo de la familia católica. La nación como proyecto cultural de inclusión ciudadana estuvo matrizado por el catolicismo tanto respecto a sus fronteras morales como legales. No es sorprendente entonces que

8 Por ejemplo, la salud en Estados Unidos o la educación en América Latina. Otro ejemplo notable es el papel de las religiones frente a la inmigración en distintos países del norte. 
las primeras reacciones frente a los movimientos feministas y por la diversidad sexual fue el considerarlos como una influencia foránea (por parte tanto de sectores conservadores como progresistas). Las demandas de estos movimientos fueron, al principio, resistidas por considerarse extranjerizantes $\mathrm{y}$, como tales, externas a los modos nacionales de parentesco, sexualidad y reproducción.

Uno de los principales impactos de los movimientos feministas y por la diversidad sexual es el haber hecho visible esta matriz de sentidos que, entre otras cosas, solapan lo religioso y lo cultural. Como lo han sostenido distintos análisis, en los contextos donde existe alguna religión mayoritaria (como el catolicismo en Francia o el protestantismo en EEUU) la influencia religiosa sobre el derecho se "camufla" (al menos parcialmente) como cultura, particularmente en temas vinculados a la sexualidad. ${ }^{9}$ Estos movimientos politizan, vuelven visibles, la influencia de la moral católica en la construcción de las dimensiones culturales de la ciudadanía. La demanda por derechos vinculados a la sexualidad interrumpe (al menos parcialmente) esta ficción evidenciando la forma en que la moral sexual católica se universaliza bajo el ropaje del ciudadano. La sexualización de la ciudadanía visibiliza y tensiona, entonces, una forma imbricada de articulación entre ciudadano y católico. Si bien esta política de desimbricación no es novedosa (se podría argumentar que con sus marchas y contramarchas viene desde el siglo XIX), los movimientos feministas y por la diversidad sexual la llevan a un nuevo umbral. Al debatirse la ciudadanía sexual se discute también el poder de la Iglesia sobre el derecho y la cultura, así como sobre las propias fronteras entre lo religioso y lo secular.

Este desmontaje entre el ciudadano y el católico, que tuvo en América Latina su propia lógica, reforzó la necesidad de una

9 En este sentido, Ann Pellegrini y J. Jakobsen (2003) observan como en los Estados Unidos las principales decisiones de la Corte Suprema vinculadas a la sexualidad se basan en los valores cristianos (de maneras más o menos explícitas). 
política identitaria por parte de la Iglesia Católica. Así como los movimientos feministas y por la diversidad sexual fueron exitosos en poner en juego "modalidades diferenciales de subjetivación" (Sabsay, 2011:27), imprimiendo un nuevo imaginario a la articulación entre estado y ciudadanía, la Iglesia Católica también ensaya nuevas formas de pertenencia comunitaria en resistencia a los DDSSRR. La Iglesia además de ser una usina moral que sostiene fronteras y construye comunidades religiosas, es una maquinaria política que produce procesos de subjetivación, identificación y trazado de fronteras que delimitan comunidades políticas. Una vez interrumpido el proyecto de la nación-católica se vuelven relevantes nuevos proyectos culturales que permitan defender la moral sexual en la construcción de la ciudadanía.

La Iglesia Católica es una institución que no sólo busca evangelizar y socializar un conjunto de valores y creencias religiosas milenarias, sino también una maquinaria de subjetivación que involucra la defensa de un proyecto cultural y de una identidad política. En este sentido, la duplicidad de creyente/ciudadano se vuelve a amalgamar en renovados marcos de sentido que trascienden lo religioso. Son dos los principales constructos que la Iglesia politiza como reacción a la ciudadanía sexual: la cultura de la muerte y la ideología de género. Ambos constructos, en gran medida generados en reacción al impacto de los movimientos feministas y por la diversidad sexual durante los 90 s en las Naciones Unidas, son utilizados en distintos contextos nacionales y transnacionales. La cultura de la muerte tiene como uno de sus principales propósitos políticos el de ofrecer un sentido renovado en defensa del derecho natural frente a las legislaciones que autonomizan la sexualidad y la reproducción. La identidad de género por su parte, permite trazar fronteras antagónicas con los movimientos feministas y por la diversidad sexual para reactivar, defensivamente, la participación de los creyentes en la defensa de un proyecto cultural amenazado.

La cultura de la muerte fue utilizada por Juan Pablo II en la encíclica Evangelium Vitae y desde allí devino en un concepto clave para comprender la política sexual de la Iglesia Católica en 
los distintos países. Según esta encíclica la cultura de la muerte implica un "concepto egoísta de libertad que ve en la procreación un obstáculo al desarrollo de la propia personalidad" (Juan Pablo II, 1995). Detrás de las demandas por el reconocimiento de derechos, la Iglesia considera la existencia de una mentalidad anticonceptiva (Juan Pablo II, 1995), que subvierte los principales valores vinculados a la familia, al sexo matrimonial o, incluso, a la complementariedad entre hombres y mujeres. Si bien la cultura de la muerte se vincula directamente al aborto y la eutanasia, lo que está en juego según la Iglesia es una 'mentalidad no reproductiva' (Juan Pablo II, 1995:13) que incluye en el mismo conjunto a la demanda por el aborto (como el asesinato de las personas más inocentes) con cualquier demanda que pretenda legitimar la separación entre sexualidad y reproducción (distinción básica para cualquier DDSSRR). El relativismo cultural, el pluralismo ético y la oposición a normas morales objetivas son consideradas como la "raíz común de todas estas tendencias" (Juan Pablo II, 1995).

El derecho (secular) es una de las principales arenas donde la Iglesia inscribe la necesidad de defender la cultura de la vida. Precisamente una característica de la cultura de la muerte es la tendencia a "exigir su legitimación jurídica" por medio de los derechos ciudadanos que el estado debe reconocer (Juan Pablo II, 1995:68). Para la Iglesia, las leyes (seculares) tienen un papel relevante, incluso determinante, en "la promoción de una mentalidad y de unas costumbres" (Juan Pablo II, 1995:90). Frente al impacto de los movimientos feministas y por la diversidad sexual, la Iglesia se activa de distintas formas en defensa de un derecho imbricado sobre la moral sexual. La Iglesia reafirma la necesidad de reconocer y respetar la ley moral objetiva que "en cuanto «ley natural» inscrita en el corazón del hombre, es punto de referencia normativa de la misma ley civil" (Juan Pablo II, 1995).

Esta apelación al derecho natural se refuerza en el uso que la Iglesia hace del discurso de los derechos humanos. Para la Iglesia, los derechos humanos "constituyen una norma objetiva que es el fundamento del derecho positivo y que no puede ser ignorada por la comunidad política" (Compendio de la Doctrina 
Social:388). Esta concepción de los derechos humanos en tanto reflejo de la ley natural, le permite a la Iglesia católica en los distintos países la defensa de una moral universal y objetiva oponiéndose así a concepciones relativistas según las cuales "el sentido y la interpretación de los derechos podrían variar, negando su universalidad en nombre de los diferentes contextos culturales, políticos, sociales e incluso religiosos" (Benedicto XVI, 2008). Es esta inseparabilidad entre derecho y moral la que resulta en un posicionamiento intransigente (integrista) de la Iglesia Católica frente a los DDSSRR. De algún modo, el uso de los derechos humanos fortaleció la transnacionalización del activismo católico conservador ya que no está (solamente) en juego la "nación católica" y el derecho interno sino, sobre todo, una comunidad internacional y el derecho que la sostiene.

El otro constructo, que ha crecido en importancia en la región durante los últimos años para trazar comunidades culturales y políticas, es la ideología de género ${ }^{10}$. Su origen es diferente al de la cultura de la muerte ya que mientras esta última se genera y reproduce desde el Vaticano y llega a los países de América Latina a través de su jerarquía, la ideología de género comienza a construirse a partir del análisis de activistas e intelectuales católicos en los Estados Unidos y se extiende luego al activismo católico y evangélicos de otros países, impactando también en la jerarquía del Vaticano y de las iglesias nacionales. Este concepto posibilita un modelo de subjetivación política que se ha ido socializando en los principales encuentros nacionales $e$ internacionales $y$ publicaciones de sectores vinculados al activismo religioso conservador. En los congresos nacionales e internacionales sobre la familia, la ideología de género ocupa un lugar relevante en las ponencias y los debates.

\footnotetext{
${ }^{10}$ En los últimos años las agendas académicas han comenzado a indagar sobre este constructo frente al impacto que tiene en la política de distintos países en América Latina, particularmente en Brasil (Miguel, 2016). La Revista Gender and Religion ha dedicado dos números especiales al debate de la ideología de género en el campo católico (ver Bracke y Paternotte, 2016).
} 
La ideología de género es un rótulo que engloba las distintas demandas de los movimientos feministas y por la diversidad sexual. En particular, se utiliza para confrontar uno de los aspectos centrales de estos movimientos: el afirmar que la sexualidad y el género son, también, construcciones culturales. Para la Iglesia Católica y el activismo católico en general, desplazar la naturaleza como eje central para entender la sexualidad implica desconocer las leyes de la naturaleza y, de este modo, negar también el plan de Dios que en ellas se reflejan. Frente al posicionamiento de estos movimientos que caracterizan como ideológica, la Iglesia Católica refuerza la defensa de la complementariedad (entre hombre y mujer) según la cual "la identidad sexual es indiscutible, porque es la condición objetiva para formar una pareja en el matrimonio" (Compendio de la Doctrina Social:496).

En Argentina, al igual que en toda Latinoamérica, la denuncia a la ideología de género es parte tanto del discurso de actores de la sociedad civil (ONGs pro-vida o pro-familia) como de la jerarquía católica. Entre los actores de ONGs católicas, el abogado Jorge Scala es uno de los pioneros en América Latina en conceptualizar la ideología de género y sus principales riesgos. En uno de sus primeros trabajos, Scala (2001) considera esta ideología como uno de los elementos de la "multinacional de la muerte" que sofistica el control de la natalidad, particularmente en el tercer mundo. Scala analiza la "llamada perspectiva de género", prestando particular atención a los trabajos de la feminista Marta Lamas, y afirma que esta perspectiva además de negar la realidad de la naturaleza humana pretende subvertir la cultura. Teniendo en cuenta tales riesgos, Scala considera que si se impusiera la ideología de género dejarían de existir el matrimonio y la familia y terminaría "colapsando la sociedad misma". ${ }^{11}$

La Iglesia Católica Argentina también ha denunciado la ideología de género, particularmente en su vinculación con la demanda por la educación sexual. Una vez reconocido el derecho de los estudiantes a recibir educación sexual en los colegios

\footnotetext{
${ }^{11}$ http://pj.gov.py/ebook/libros_files/Ponencia_Jorge_Scala_Género.pdf
} 
privados y públicos (año 2006), la Iglesia Católica se manifestó públicamente en contra de los contenidos mínimos propuestos por parte del Ministerio de Educación. En particular rechazó que se incluyera la no discriminación por género por considerar que distorsiona la educación sexual. Este principio expresa, según la Iglesia, una "ideología de género" opuesta a la "realidad de la naturaleza humana ya que el hombre desde su concepción biológica es sexuado, varón o mujer; y por ende esta inclusión posibilita una distorsión en la educación sexual" (Conferencia Episcopal Argentina, 2008).

Tanto la cultura de la muerte como la ideología de género, de manera diferente pero complementaria, tienen un papel relevante en la construcción de una pertenencia cultural para los ciudadanos. En ambos casos se construye una pertenencia comunitaria, una identidad, que se ve amenazada por las demandas "anti-naturales" de los movimientos feministas y por la diversidad sexual. La defensa de la cultura de la vida le permite a la jerarquía católica poner en funcionamiento un aparato políticolegal destinado a oponerse a la ciudadanía sexual. La defensa de la vida habilita a un proceso de re-naturalización del derecho en oposición a los DDSSRR. La ideología de género, por su parte, potencia esta construcción antagónica proponiendo un modelo de subjetivación política, de movilización ciudadana en defensa de la naturaleza humana. La articulación de una política identitaria en defensa de un modelo de familia natural se consolida en reacción a esta ideología y sus portadores. La ideología de género permite trazar nuevas fronteras al desarticularse el imaginario de la nacióncatólica.

La cultura de la vida y la ideología de género posibilitan un proyecto cultural que rearticula una categoría de ciudadano/creyente que no sólo es ecuménica (incluye también a aquellos que no son católicos) sino también transnacional. No está en juego la nación católica sino la comunidad religiosa global. Como veremos en la próxima sección, esta construcción antagónica se manifiesta en las formas en que la jerarquía católica 
convoca a los creyentes, en tanto ciudadanos, a ser activos en la política sexual contemporánea.

\section{b. La ciudadanía como práctica: movilización de las creencias religiosas}

Una de las principales facetas de la ciudadanía se vincula con el derecho a ser un partícipe activo en la toma de decisiones públicas y en las principales instituciones políticas. Lo religioso ha tenido (en general) una influencia relevante en las prácticas y opiniones ciudadanas que se plasma con mayor intensidad en aquellos debates vinculados a las formas de regular el orden sexual. Si bien esta influencia es compleja y apunta en diferentes direcciones, la mayoría de los estudios señalan las formas en que la influencia religiosa sostiene un régimen de exclusión y discriminación respecto a la ciudadanía sexual (Vaggione, 2011b). Esta oposición entre influencia religiosa y democratización de la sexualidad se analiza tanto a nivel del estado y de las leyes como de los individuos y su posicionamiento hacia los DDSSRR. ${ }^{12}$

A pesar de la relevancia de las creencias religiosas en la participación y movilización ciudadana, su influencia fue (en general) construida en tensión con una política democrática. El secularismo como ideología de la modernidad marcó, de forma determinante, las fronteras entre ciudadano y creyente (Calhoun, 2011). La formulación clásica de la ciudadanía implicaba la exclusión de las creencias religiosas: el ciudadano es un modelo "universal" incompatible con las particularidades de lo religioso. En gran medida este debate gira en torno a la posibilidad (o no) de que los ciudadanos que son creyentes defiendan públicamente sus posiciones con argumentaciones religiosas. Este es un debate complejo que excede los propósitos de este artículo, pero puede afirmarse que aquellas posturas que sostienen la exclusión de las creencias religiosas de la ciudadanía han comenzado a ser críticamente revisadas. Frente a los posicionamientos más

\footnotetext{
${ }^{12}$ Tanto investigaciones cualitativas como cuantitativas han puesto de manifiesto este aspecto.
} 
secularistas, una serie de autores reconocen (y buscan subsanar) la carga desigual con que se coloca a algunos ciudadanos debido a sus creencias religiosas. Se legitiman de este modo diferentes formas de las argumentaciones y razones religiosas como parte de los debates públicos. ${ }^{13}$

El catolicismo es, sin dudas, una tradición con un peso relevante en las prácticas e identidades ciudadanas. Si bien la Iglesia Católica distingue entre el ciudadano y el creyente, defiende un modelo de imbricación entre ambos. La Iglesia convoca al creyente a participar políticamente en defensa del bien común "de acuerdo con su conciencia cristiana" (Congregación para la Doctrina de la fe, 2002). Conceptos como "fiel laico" utilizados en distintos documentos evidencian la poca relevancia o incluso inexistencia de las fronteras entre ciudadano y creyente. Como lo expresara Juan Pablo II, los fieles laicos están marcados por una unidad ya que son miembros de la Iglesia y "ciudadanos de la sociedad humana" (Juan Pablo II, 1988). El compendio de la Doctrina Social convoca al fiel laico a poner en práctica los principios y valores morales frente a las distintas situaciones políticas (Compendio de la Doctrina Social:568). Incluso la Iglesia sostiene que la conciencia cristiana no permite "favorecer con el propio voto la realización de un programa político o la aprobación de una ley particular que contengan propuestas alternativas o contrarias a los contenidos fundamentales de la fe y la moral" (Congregación para la Doctrina de la Fe, 2002). Según Benedicto XVI es importante que los ciudadanos en tanto creyentes, actúen en base a los principios morales ya que "los católicos tenemos no sólo el derecho, como todo ciudadano, sino también la obligación de hacer nuestro aporte al debate público". ${ }^{14}$

\footnotetext{
${ }^{13}$ Un ejemplo en esta dirección es J. Habermas quien abre a un momento postsecular ya que considera pertinente que los ciudadanos, en tanto creyentes, puedan articular públicamente sus motivaciones.

${ }^{14} \mathrm{http}$ ://www.episcopado.org/portal/actualidad-cea/oficina-de-prensa/item/705-elcódigo-civil-y-nuestro-estilo-de-vida.html
} 
Esta imbricación entre ciudadano y creyente se intensifica cuando se debate públicamente la sexualidad. Particularmente desde los 90 s la Iglesia Católica ${ }^{15}$ priorizó la movilización de ciudadanos/creyentes (fieles laicos) en defensa de la moral sexual que consideraba amenazada por el avance de los DDSSRR. Estas "exigencias éticas fundamentales e irrenunciables", que requieren de una activa participación del ciudadano/creyente se vinculan, directamente, a los espacios legales en disputa por parte de los movimientos feministas y por la diversidad sexual (Congregación para la Doctrina de la Fe, 2002). La Iglesia menciona, por ejemplo, entre estas exigencias el derecho primario a la vida desde su concepción hasta su término natural, el deber de respetar y proteger los derechos del embrión humano, la tutela y la promoción de la familia, fundada en el matrimonio monógamo entre personas de sexo opuesto, la libertad de los padres en la educación de sus hijos y la liberación de las víctimas de las modernas formas de esclavitud (mencionándose expresamente la droga y la prostitución) (Congregación para la Doctrina de la Fe, 2002).

Esta imbricación se traduce en la movilización de las creencias religiosas como un aspecto central de la política sexual de la Iglesia Católica (a nivel transnacional y nacional). El ciudadano es llamado a movilizarse en tanto creyente para evitar o revertir la vigencia de los DDSSRR. Frente a la sexualización de la ciudadanía, la Iglesia Católica politiza las creencias religiosas de los ciudadanos en defensa de un orden moral basado en el acto sexual dentro del matrimonio y abierto a la reproducción. En Argentina, al igual que en los países de la región, es posible observar tres sectores de la ciudadanía que la Iglesia Católica prioriza cuando moviliza las creencias religiosas contra los DDSSRR. En primer lugar, la Iglesia Católica convoca a los fieleslaicos, en tanto parte de la sociedad civil, a movilizarse en defensa de la "cultura de la vida". Para la Iglesia, la sociedad civil tiene un

\footnotetext{
15 bajo el gobierno de Juan Pablo II y Ratzinger (primero como prefecto de la fe y luego como papa).
} 
lugar privilegiado ya que la comunidad política tiene que estar a su servicio y de las "personas y de los grupos que la componen" (Compendio de la Doctrina Social:418). Una de las manifestaciones de esta movilización es la conformación y crecimiento de organizaciones no gubernamentales (ONGs) auto-denominadas pro-vida o pro-familia. Este proceso de ONGinización de lo religioso es una de las principales caras del activismo católico conservador en América Latina (Vaggione, 2005). La priorización que la Iglesia Católica hizo de la sexualidad fue acompañada del sostenimiento de espacios nacionales y transnacionales para facilitar y consolidar este activismo. ${ }^{16} \mathrm{Si}$ bien estas ONGs surgen en respuesta al llamado de la Iglesia Católica, visibilizan su conexión con lo religioso de forma diferente. En Argentina, por ejemplo, algunas se auto-identifican públicamente como católicas incluso en el mismo nombre elegido (por ejemplo el Consorcio de Médicos Católicos, la Asociación de Abogados Católicos o Portal de Belén); otras, en cambio, se presentan como ecuménicas, o incluso como no religiosas (aunque sus integrantes son en general católicos). El desplazamiento hacia estas organizaciones ha tenido diversas consecuencias sobre el activismo católico conservador entre las que se destacan su mayor profesionalización, la intensificación de sus alianzas con sectores evangélicos y la federalización de su política (Morán Faúndes et al., 2016).

Estas ONGs han adquirido un creciente protagonismo en la política sexual para evitar o revertir los DDSSRR. Frente a discusiones vinculadas a la anticoncepción, la educación sexual, los derechos para parejas del mismo sexo o la despenalización del aborto (entre otras) estas organizaciones lideran el activismo católico. Un propósito central de las mismas es impactar sobre la sanción e interpretación del derecho. Como parte de la sociedad civil, estas ONGs realizan diversas actividades e implementan distintas estrategias para canalizar políticamente su influencia. Como ejemplos de Argentina pueden mencionarse la movilización

\footnotetext{
${ }^{16}$ Un ejemplo de estos espacios el Encuentro Mundial de las Familias que se realiza cada tres años desde 1994.
} 
callejera en los momentos de debates parlamentarios, la instrumentación de campañas públicas en contra de los DDSSRR o la participación de sus integrantes como expertos en distintos espacios de debates en contra de las políticas públicas para evitar su implementación. En particular la judicialización de los DDSSRR es una de las principales estrategias de estas organizaciones al presentar, por ejemplo, distintos recursos de amparo con el propósito de interrumpir leyes que amplían los DDSSRR (Peñas Defagó et al., 2014). Si bien algunas de estas organizaciones tienen ya varias décadas de existencia, la mayoría han surgido en reacción a la política sexual iniciada en las últimas dos décadas en Argentina, particularmente frente a la politización del aborto y de los derechos para las parejas del mismo sexo (Morán Faúndes et al., 2016).

En segundo lugar, la Iglesia Católica llama a los gobernantes, legisladores y jueces, en tantos fieles laicos, a defender la moral sexual católica y evitar la vigencia de los DDSSRR. El aborto y el reconocimiento de derechos para las parejas del mismo sexo son dos temáticas para las cuales la Iglesia Católica presenta instrucciones precisas de cómo deben actuar los ciudadanos/creyentes involucrados en el proceso de sanción, aplicación o instrumentación del derecho. La Iglesia señala que estos funcionarios deben manifestar su oposición clara y pública a estas leyes y, cuando no se pueden evitar y ya son legislaciones vigentes, los funcionarios pueden apoyar propuestas encaminadas a "disminuir sus efectos negativos en el campo de la cultura y de la moralidad pública" (Congregación para la Doctrina de la Fe, 2002).

Debido al desguace de partidos políticos de corte católico (la democracia cristiana sólo continúa de manera excepcional en algunos países) se convoca a funcionarios y políticos de diversos partidos políticos en tanto creyentes. Así, en Argentina líderes políticos de distintas filiaciones partidarias defienden públicamente los principios católicos al momento de debatir los DDSSRR (Sgro et al., 2012). La convocatoria por parte de la jerarquía católica se produce tanto activando canales privados como públicos. Entre los primeros, son comunes las conversaciones y reuniones privadas 
entre líderes políticos y la jerarquía eclesial. Frente al debate sobre la sexualidad, las pertenencias partidarias parecen dar lugar a las 'convicciones personales', a la moral de los políticos. Al debatirse la ley de matrimonio para parejas del mismo sexo, por ejemplo, los jefes de bloque partidario sostuvieron la "libertad de conciencia" respecto a la decisión de cada legislador; como si la sexualidad fuera el único clivaje donde la moral prevalece sobre la política, donde los posicionamientos personales se vuelven centrales frente a los bloques partidarios.

Pero también la Iglesia activa canales públicos a través de cartas $^{17}$, exhortaciones ${ }^{18}$, documentos oficiales y discursos ${ }^{19}$ de sus representantes destinados a influenciar el posicionamiento de los distintos operadores del derecho. Al momento de debatirse leyes vinculadas a los DDSSRR, como el matrimonio igualitario en el año 2010, es posible observar las formas en que algunos legisladores se auto-identifican como católicos en defensa de los principios defendidos por la Iglesia. Sin embargo las formas en que politizan sus creencias son diferentes. Algunos, al momento de rechazar públicamente esta legislación, refieren a sus motivaciones y razones religiosas, incluyendo incluso referencias a la doctrina oficial o los documentos de la Iglesia. Otros en cambio, al momento de argumentar públicamente, utilizan un arsenal de justificaciones seculares sin necesidad de incluir referencias específicamente religiosas (Vaggione, 2011a). Este último tipo de político católico es el emergente de la política sexual contemporánea, ya que combina una fuerte influencia de las creencias religiosas con un desplazamiento de las mismas en tanto

\footnotetext{
${ }^{17}$ Cartas directas a legisladores y ministros en contra de proyectos de leyes. A continuación algunos ejemplos: http://www.notivida.net/boletines/103 .html; "La buena noticia de la vida humana y el valor de la sexualidad"; http://aica.org/aica/documentos_files/CEA/Comision_Ejecutiva/Carta_salud.htm

${ }^{18}$ http://www.episcopado.org/portal/actualidad-cea/oficina-de-prensa/item/705-elcódigo-civil-y-nuestro-estilo-de-vida.html

${ }^{19}<$ http://www.episcopado.org/portal/actualidad-cea/oficina-de-prensa/item/868declaración-sobre-el-tema-del-aborto-mons-arancedo,-arzobispo-de-santafe.html>
} 
operador del derecho. Mientras que en el primer tipo hay una indeterminación de roles (el legislador vota como creyente), en el segundo se reconocen los diferentes roles, no se justifica el voto desde las creencias religiosas sino a partir del arsenal de argumentaciones seculares generadas y circuladas por la misma jerarquía católica (Vaggione, 2011a).

Finalmente, la Iglesia también convoca a los intelectuales y académicos a contribuir en la defensa de la moral católica. El activismo católico conservador reconoce la importancia que tienen los centros académicos en la producción y circulación de discursos en defensa de la vida. Una de las estrategias para confrontar la ciudadanía sexual es, precisamente, 'conocer racionalmente' las leyes de la naturaleza que deben ser el basamento del derecho (secular). Para potenciar esta estrategia el Vaticano crea en el año 1994 la Pontificia Academia para la Vida, que tiene como misión promover las distintas ciencias (sociales, económicas, políticas y jurídicas) a la "luz de la doctrina social de la Iglesia". ${ }^{20}$ Como parte de sus actividades, se propone la organización de encuentros nacionales e internacionales, el estudio de las legislaciones y líneas de pensamiento que afectan la cultura de la vida, la publicación y diseminación de investigaciones, y estimular la participación de sus miembros en los principales iniciativas nacionales $e$ internacionales vinculadas a los propósitos de la Academia. ${ }^{21}$

Es habitual en América Latina que, frente a los debates sobre los DDSSRR, distintos académicos e intelectuales identificados con el catolicismo produzcan, circulen y/o defiendan investigaciones científicas en línea con la moral sexual católica. En particular, algunas universidades católicas son usinas de discursos y posicionamientos académicos durante los debates sobre la regulación de la sexualidad. En Argentina, al debatirse la ley de

\footnotetext{
${ }^{20}$ http://www.vatican.va/roman_curia/pontifical academies/acdlife/documents/rc p a acdlife pro 20051996 sp.html 21
}

http://academiavita.org/_image/about_us/_documents/_statute/academy_statute.p $\mathrm{df}$ 
matrimonio para parejas del mismo sexo (2010), la Universidad Austral (vinculada al Opus Dei) circuló un informe de estudios científicos y jurídicos argumentando el rechazo de la reforma legal. ${ }^{22}$ Otro ejemplo es la conformación en el año 2006 de la Cátedra Internacional Ley Natural y Persona Humana en la Universidad Católica Argentina, en respuesta a la convocatoria de Benedicto XVI a que las "diversas universidades católicas en todo el mundo a colaborar en el estudio de la presencia de los contenidos esenciales de la ley moral natural en la sociedad contemporánea". ${ }^{23}$

Las creencias de los ciudadanos se movilizan en defensa de la "cultura de la vida", frente la ampliación de derechos vinculados a la sexualidad y la reproducción. La movilización política de las creencias no es un fenómeno novedoso, sin embargo, la temporalidad abierta por los movimientos feministas y por la diversidad sexual genera rearticulaciones y nuevas dinámicas en la construcción de una ciudadanía. Por un lado, hay una movilización de creencias interconectada en distintas arenas (sociedad civil, sociedad política y la academia) que potencia la construcción de un activismo político integrado. Por otro lado, esta movilización da lugar a formas más sofisticadas de participación como son la judicialización por parte de las ONGs, la presencia de políticos católicos 'secularizados' o el modelo argumental que distingue, sin separar, las razones religiosas y las seculares. La distinción entre ciudadano y creyente, marcada de diferentes formas, se desvanece en la politización de un modelo de imbricación entre ambas facetas.

\section{c. La ciudadanía como derecho: la legalización de las creencias religiosas}

Otra dimensión de la ciudadanía que permite comprender la política religiosa contemporánea es considerarla como generadora

\footnotetext{
22 "Matrimonio homosexual y adopción por parejas del mismo sexo".

$23 \mathrm{http}: / / w w w . u c a . e d u . a r / i n d e x . p h p / s i t e /$ index/es/uca/catedra-internacional-leynatural-y-persona-humana/nuestra-catedra/
} 
de derechos y obligaciones. Esta dimensión, priorizada en la mayoría de los análisis, aborda a la ciudadanía como un status formal conectado a derechos y obligaciones. El abordaje clásico de T.H. Marshall (1950) ubica a los derechos civiles como aquellos destinados a proteger la libertad individual y por tanto garantizar la libertad de pensamiento, de expresión y de creencias (entre otras). La libertad religiosa, de culto y/o de conciencia se constituyen en pilares del derecho, generalmente incorporados en las cartas magnas de los distintos países. El contenido de estas libertades es reforzado en distintas instancias nacionales $y$ transnacionales $^{24}$ por medio de tratados, leyes y casos jurisprudenciales. ${ }^{25}$

Si bien la libertad religiosa está protegida por el derecho de cada país y el internacional, la interpretación sobre su alcance es dinámica y responde a distintas coyunturas. El avance logrado por los movimientos feministas y por la diversidad sexual es una de estas coyunturas ya que ha generado que se repolitizaran la libertad religiosa y los derechos correspondientes con el propósito de ampliar su cobertura y protección. La legitimación de los derechos sexuales y reproductivos es considerada por algunos sectores como una amenaza al libre ejercicio de las creencias religiosas. Así, el derecho de una pareja del mismo sexo al matrimonio, de una mujer a ligar sus trompas o de un adolescente a recibir educación sexual, por ejemplo, se consideran en tensión con la libertad y los derechos religiosos de otros ciudadanos: el funcionario público encargado de celebrar un acto administrativo, el médico que debe llevar adelante una intervención quirúrgica o los padres que quieren decidir el tipo de educación para sus hijos.

\footnotetext{
${ }^{24}$ De particular importancia es la "Declaración Universal de los Derechos Humanos", aprobada por la Asamblea General de la Organización de las Naciones Unidas, el 10 de diciembre de 1948.

${ }^{25}$ Por ejemplo la doctrina ha identificado un aspecto interno vinculado al derecho a mantener o no las creencias religiosas y otro externo que implica el derecho a profesar públicamente y divulgar dichas creencias. Bidart Campos (1998), Fernando Arlettaz (2012).
} 
La ciudadanía como estatus formal se transforma en un campo simbólico de batalla entre los derechos sexuales y reproductivos y los derechos religiosos. La Iglesia Católica es un actor relevante de este proceso ya que ha repolitizado la defensa de la libertad y derechos religiosos en oposición a los movimientos feministas y por la diversidad sexual. La Iglesia defiende el derecho a la libertad religiosa en sus manifestaciones individuales y comunitarias y considera que este derecho debe ser "reconocido en el ordenamiento jurídico y sancionado como derecho civil" (Compendio de la Doctrina Social de la Iglesia:862). Bajo el concepto de libertad religiosa se incorporan, sin embargo, no sólo la libertad de creencias como aspecto interno y de cultos como expresión externa $^{26}$ sino también la "posibilidad de que los creyentes contribuyan la construcción del orden social" (Benedicto XVI, 2008). No deja de ser llamativo que, en pocas décadas, el Vaticano haya pasado de rechazar la libertad religiosa ${ }^{27}$ a considerarla un derecho humano fundamental y un resguardo no sólo para el libre ejercicio de las creencias sino también para la participación en la vida pública de la Iglesia y de los creyentes.

La libertad religiosa está, también, en un proceso de (re)interpretación en América Latina. De ser resistida por la Iglesia Católica, ya que se utilizaba para evidenciar su estatus privilegiado frente a otras tradiciones religiosas, pasó a ser estratégicamente usada por sectores religiosos conservadores (tanto del campo evangélico como del católico) en resistencia a los DDSSRR. Las demandas de los movimientos feministas y por la diversidad sexual, en tanto portadoras de un "secularismo radical" se consideran como amenazas a la libertad religiosa. En Argentina la politización de la libertad y de los derechos religiosos se presenta de diferentes formas, aunque interconectadas. Una de las formas es defender la libertad religiosa de los padres para educar a los hijos de acuerdo a su propio sistema de valores y creencias (Peñas

\footnotetext{
${ }^{26}$ Ver nota 25.

${ }^{27}$ Recién acepta la libertad religiosa con la Encíclica "Dignitatis humanae" (1965) durante el Concilio Vaticano II.
} 
Defagó et. al., 2014). La patria potestad y el interés superior del niño se amalgaman con la libertad religiosa para resistir la vigencia de los DDSSRR. El paradigma de los DDSSRR incluye como ciudadanos con derechos a los menores de edad (niños y jóvenes) teniendo en cuenta su desarrollo y capacidades. Ejemplo de esto son la ley de educación sexual integral (aprobada en el 2006) que considera que todo niño, joven o adulto, en el sistema educativo tiene el derecho a recibir educación vinculada a la sexualidad y el programa nacional de educación sexual y procreación responsable (del año 2003) que está destinado a la población en general y, entre su articulado, también incluye a los menores de edad "en consonancia con la evolución de sus facultades" ${ }^{28}$. El activismo católico critica estas legislaciones por considerar, entre otras cuestiones, que vulneran la libertad religiosa de los progenitores como un derecho humano fundamental. En este sentido se han presentado una serie de recursos de amparo contra las legislaciones que habilitan el acceso de menores de 18 años a anticonceptivos, basados en la violación a la libertad religiosa de los progenitores (Peñas Defagó et al., 2014).

La redefinición de la objeción de conciencia es otra estrategia de impacto en la región, para la expansión de derechos vinculados al ejercicio de las creencias religiosas. La objeción de conciencia tiene como propósito eximir a un individuo de cumplimentar con una ley en caso que la acción afecte sus íntimas convicciones y que dicha eximición no cause daños a terceros (Alegre 2009, Arlettaz 2012). La excepción del servicio militar obligatorio ha sido uno de los principales supuestos de su aplicación como forma de proteger convicciones antimilitaristas o pacifistas..$^{29}$ Sin embargo, durante los últimos años, la objeción de conciencia comenzó a tener un creciente protagonismo como estrategia para oponerse a la legitimidad de los DDSSRR (Alegre

\footnotetext{
${ }^{28}$ Decreto Nacional 1.282/2003.

${ }^{29}$ El fallo Portillo de la Corte Suprema Argentina reconoció el derecho a no usar armas durante el servicio militar fundamentado por la libertad de conciencia (Caso Portillo, Alfredo s/infr. Art. 44 ley 17.531, Fallos 312:496).
} 
2009, Puga y Vaggione, 2013). En Argentina, como en la región en general, la aprobación de leyes vinculadas a los DDSSRR fue acompañada por una creciente politización de la protección de las creencias, especialmente religiosas, de los ciudadanos encargados de aplicar y/o implementar estas legislaciones.

La Iglesia Católica, tanto en Argentina como en la región, lidera la defensa de la objeción de conciencia en reacción a los DDSSRR. Siguiendo el posicionamiento del Vaticano, la Iglesia en los distintos países considera ilegítimos a estos derechos por violar el derecho natural frente a lo cual la objeción de conciencia se inscribe como la (única) opción moral para los ciudadanos/creyentes. Los principales documentos afirman que esta objeción no es sólo un derecho sino un deber del ciudadano/creyente, frente a las leyes que contrariando la cultura de la vida carecen de legitimidad y deben ser desobedecidas (Puga y Vaggione, 2013). Si bien el objetivo de la objeción de conciencia es conciliar la existencia de ciertas leyes frente a las convicciones individuales, la forma en que el activismo católico conservador la utiliza pone en tensión la propia legitimidad del derecho.

En la política sexual argentina, como en la de otros países, la objeción de conciencia funciona como una estrategia que no sólo busca dificultar sino impedir la vigencia de los DDSSRR. Tiene el propósito de proteger derechos individuales pero en un plano político persigue la deslegitimación de derechos ya reconocidos, desvirtuando el propósito de la objeción como instituto legal. Cuando no se puede evitar el reconocimiento de algún DDSSRR, la estrategia de este sector es ampliar la objeción de conciencia como un derecho humano fundamental. Entre los principales ejemplos pueden considerarse la politización de la objeción de conciencia como un derecho institucional para hospitales $y$ clínicas, además de ser un derecho individual (Conferencia Episcopal Argentina, 2015) o el rechazo a la ley de matrimonio para parejas del mismo sexo, por no incluir la objeción de conciencia de los funcionarios del registro civil. También se han iniciado distintos procedimientos judiciales, en general por parte de las ONGs pro-vida/pro-familia, para ampliar el reconocimiento de la 
OC frente a las legislaciones (nacionales o provinciales) que reconocen el acceso ciudadano a diversos métodos anticonceptivos.

El derecho es, por definición, indeterminado y su interpretación y alcance responde no sólo a las reglas legales y al papel de sus operadores sino también a los cambiantes contextos políticos. $^{30}$ Precisamente la interpretación de los derechos vinculados a la ciudadanía religiosa está atravesando una temporalidad novedosa respecto a su protección y alcance. Estos derechos ya no (sólo) se utilizan para ampliar espacios de libertad individual para los creyentes sino también para reducir la legitimidad (incluso legalidad) de los derechos vinculados a la sexualidad y la reproducción. ${ }^{31}$ El derecho de los ciudadanos a las creencias religiosas (a tenerlas y expresarlas) se politiza en contraposición a los derechos sexuales y reproductivos. Este viraje expone una especie de camuflaje por el cual la defensa de derechos que buscan proteger la libertad individual o de conciencia de determinados individuos, también tienen como propósito confrontar la legitimidad de las legislaciones que amplían la ciudadanía sexual.

\section{Conclusiones}

Los movimientos feministas y por la diversidad sexual han logrado incluir la sexualidad en la arena pública, lo que también ha generado sostenidas resistencias, particularmente en el campo religioso, que condicionan el alcance de la política sexual

\footnotetext{
${ }^{30}$ Bourdieu (2001) desarrolla el concepto de autonomía relativa del campo jurídico para incluir, precisamente, tanto las lógicas internas como las externas.

${ }^{31} \mathrm{Un}$ proceso similar se produce en Estados Unidos donde se debate judicialmente la tensión entre dos valores legales: por un lado, la libertad religiosa o libertad de culto y por otro lado la igualdad (en particular de la comunidad LGBT y de las mujeres). Un caso jurisprudencial de fuerte impacto en este sentido es Burwell v. Hobby Lobby por el cual la Corte Suprema de los Estados Unidos autoriza a una empresa familiar a exceptuarse de cumplir con la obligación de proveer contraceptivos a las empleadas por razones religiosas.
} 
contemporánea. El debate sobre las formas de regular la sexualidad en distintos países de América Latina, a veces acompañado por la ampliación de derechos, ha dado lugar a intensas re-acciones por parte de la Iglesia Católica y sectores aliados. Este artículo propuso el concepto de ciudadanía para identificar algunos de los rasgos de la política de la Iglesia Católica contraria a los DDSSRR. Así como el impacto de estos movimientos ha sido comprendido (en sus potencialidades $y$ limitaciones) a partir del concepto de ciudadanía, también las rearticulaciones del poder religioso pueden ser pensadas en conexión con este concepto.

En particular se presentaron tres dimensiones que caracterizan el proceso de consolidación de la ciudadanía religiosa. En primer lugar, se analizaron las estrategias identitarias vinculadas a procesos de subjetivación a través de la construcción de dos amenazas: la cultura de la muerte y la ideología de género. Interrumpido, o al menos fisurado, el proyecto de nación católica, la Iglesia Católica apela a nuevos clivajes identitarios que permiten la politización de comunidades morales, esta vez ecuménicas y transnacionales. En segundo lugar, se profundizaron las formas en que la Iglesia Católica moviliza a los ciudadanos en tanto creyentes. Distintos sectores de la sociedad civil y política son efectivamente convocados en tanto "fieles laicos" a la defensa de un orden sexual (y social). Finalmente, se consideró la politización de los derechos religiosos como forma de confrontar las demandas de los movimientos feministas y por la diversidad sexual. El activismo católico re-interpreta y expande el alcance de la libertad religiosa y de conciencia como estrategia de resistencia a la sexualización de la ciudadanía.

Estas dimensiones ponen en evidencia una dinámica de reconfiguración de la ciudadanía determinada por lo religioso, que tiene como eje articulador la defensa de un orden moral universal. La Iglesia Católica ya no es (o no solamente es) una religión que controla (legal y culturalmente) los límites morales de la nación católica sino una maquinaria política que defiende las creencias religiosas frente a amenazas, tanto reales como imaginarias, de los 
movimientos feministas y por la diversidad sexual. El corrimiento de los límites de la ciudadanía para incluir al cuerpo sexuado ha detonado un proceso de politización de las creencias como medulares a la condición de ciudadano. La Iglesia Católica lejos de renunciar a la vigilancia sobre el cuerpo sexuado, sofistica sus estrategias proponiendo nuevas formas de imbricación entre el ciudadano y el creyente que se manifiestan en las identidades, en las prácticas y en el reconocimiento de derechos.

\section{Referencias bibliográficas}

AlEgRE, Marcelo. Opresión de Conciencia: El problema de la OC en la esfera de la Salud Sexual y Reproductiva. SELA (Seminario en Latinoamérica de Teoría Constitucional y Política), Yale Law School, 2009.

ARLETTAZ, Fernando. Libertad Religiosa y objeción de conciencia en el Derecho Constitucional Argentino. Estudios Constitucionales, Año 10, $\mathrm{n}^{\circ}$ 1, 2012, pp.339-372. ISSN 0718-0195 Centro de Estudios Constitucionales de Chile Universidad de Talca, 2012.

BRACKE, Sarah; PATERNOTTE, David. (guest editors) Habemus Gender! The Catholic Church and 'Gender Ideology'. Religion and Gender, 6 (volume 1, 2), 2016.

BOtTOMORE, Tom. Citizenship and Social Class, Forty Years On. En: BotTOMORE, Tom; MARShall, T.H.; MoORE, Robert. (ed.) Citizenship and Social Class. Pluto Press, 1992, pp.53-93.

BouRdiEU, Pierre. La fuerza del derecho. Elementos para una sociología del campo jurídico. En: BouRdieu, Pierre. Poder, Derecho y clases sociales. Desclée, España, 2001, pp.165-223.

Calmoun, Craig. Secularism, Citizenship, and the Public Sphere. En: CALHOUn, Craig; JUERGENSMEYER, Mark; VANANTWERPEN, Jonathan. Rethinking Secularism. Oxford University Press, Oxford and New York, 2011.

CARRARA, Sérgio. Moralidades, Racionalidades e Políticas sexuais no Brasil Contemporáneo. Mana, vol.21, n² 2, 2015, pp.323-345. 
cadernos pagu (50), 2017:e175002 La Iglesia Católica frente a la política sexual

CASANOVA, José. Public religions in the modern world. Chicago, University of Chicago Press, 1994.

COHEN, J. Changing Paradigms of Citizenship and the Exclusiveness of the Demos. International Sociology, 14 (3), 1999, pp.245-268.

Hudson, W. Religious Citizenship. Australian Journal of Politics and History, 49 (3), 2003, pp.425-429.

FRASER, Nancy; GORDON Linda. Contract versus Charity: Why is There no Social Citizenship in the United States? En: The Citizenship Debate, pp.113-127.

JAKOBSEN, Janet; PELLEGRINI, Ann. Love the Sin. Sexual regulation and the limits of Religious Tolerance, New York University Press, New York, 2003.

KYMLICKA, Will; NORMAN. Waine. Citizenship in Culturally Diverse Societies: Issues, Contexts, Concepts. In: KYMLICKA, W.; NORMAN, W. (eds.) Citizenship in Diverse Societies. Oxford, Oxford University Press, 2000, pp.1-41.

LEYDET, Dominique. Citizenship. The Stanford Encyclopedia of Philosophy, Edward N. Zalta (ed.), Spring 2014 [https://plato.stanford.edu/archives/spr2014/entries/citizenship/].

LISTER, Ruth Citizenship: Feminist Perspectives. London, MacMillan, 1997.

LISTER, Ruth. Sexual Citizenship. En: ISIN EngIN, F.; TURNER, Bryan S. (eds). Handbook of Citizenship Studies. London, Sage, 2002, pp.191207.

Marshall, T. H. Citizenship and Social Class and Other Essays. Cambridge, Cambridge University Press, 1950.

Miguel, Luis Felipe. Da "doutrinação marxista" à "ideologia de gênero" Escola Sem Partido e as leis da mordaça no parlamento brasileiro. Direito \& Praxis, vol. 07, n 15, Rio de Janeiro, 2016, pp.590-621.

Moran Faundes, José M.; PeÑas Defago, María Angélica. Strategies of Self-Proclaimed Pro-Life Groups in Argentina. Effect of New Religious Actors on Sexual Policies. Latin American Perspectives, Issue 208, vol. 43, n 3, May 2016, pp.144-162. 
NYHAGEN, Line Conceptualizing lived religious citizenship: a casestudy of Christian and Muslim women in Norway and the United Kingdom. Citizenship Studies, vol. 19, Iss. 6-7, 2015.

PEÑAS Defago, María Angélica; MoRAN FAUNDES, José Manuel. Conservative litigation against sexual and reproductive health policies in Argentina. Reproductive Health Matters, 22, 2014, pp.82-90.

Permoser, J. M.; RosenberGer, S. Religious Citizenship as a Substitute for Immigrant Integration? The Governance of Diversity in Austria. In: GuiLD, E.; GROENENDIJK, K.; CARRERA, S. (ed.). Illiberal Liberal States. Aldershot, Ashgate, 2009, pp.149-166.

Plummer, Ken. Intimate Citizenship: Private Decisions and Public Dialogues. Montreal \& Kingston, McGill-Queen's University Press, 2003.

PugA, Mariela; VAGGIONE, Juan Marco. La política de la conciencia. La objeción como estrategia contra los derechos sexuales y reproductivos. En: VASSALLO, Marta (compiladora) Peripecias en la lucha por el derecho al aborto, Ferreyra Editor, 2013.

SABSAY, Leticia. Fronteras Sexuales. Espacio urbano, cuerpos y ciudadanía, Buenos Aires, Paidós, 2011.

ScalA, Jorge. Género y Derechos humanos. San José, Costa Rica. Ediciones PROMESA, 2001.

TURNER, Bryan. Outline of a theory of citizenship. Sociology, 1990, pp.189-217.

Vaggione, Juan Marco. Reactive Politicization and Religious Dissidence: The Political Mutations of the Religious. Social Theory and Practice, vol. 31, n 2, 2005, pp.165-188.

VAggione, Juan Marco. Sexual Rights and Religion: Same-sex Marriage and Lawmakers' Catholic Identity in Argentina. University of Miami Law Review, vol. 65, n³, 2011 a.

VAggione, Juan Marco. Sexualidad, Religión y Política en América Latina. En: CORRÊA, Sonia; PARKER, Richard. (orgs.) Sexualidade e política na América Latina: histórias, interseçóes e paradoxos, Sexuality Policy Watch, Río de Janeiro, 2011b, pp.286-336. 
cadernos pagu (50), 2017:e175002 La Iglesia Católica frente a la política sexual

VAgGione, Juan Marco. Laicidad y sexualidad. Ciudad de México, Unam, 2013.

YUVAL-DAVIS, N. The 'Multi-Layered Citizen'. International Feminist Journal of Politics, 1 (1) , 1999, pp.119-136.

Yuval-Davis, N. Belonging and the Politics of Belonging. Patterns of Prejudice, 40 (3), 2006, pp.197-214.

\section{Documentos}

BENEDICTO XVI, Nueva York, Viernes 18 de abril de 2008 [https://w2.vatican.va/content/benedict[xvi/es/speeches/2008/april/documents/hf_benxvi_spe_20080418_un-visit.html - fecha de consulta: 3 enero 2017].

COMPENDIO de la Doctrina Social de la Iglesia [http://www.vatican.va/roman_curia/pontifical_councils/justpeace/doc uments/rc_pc_justpeace_doc_20060526_compendio-dott-soc_sp.html - fecha de consulta: 3 enero 2017].

CONFERENCIA Episcopal Argentina. Ante la aprobación de los lineamientos curriculares para la educación sexual integral, 2008 [http://www.aicaold.com.ar//index2.php?pag=CEEC080617 - fecha de consulta: 3 enero 2017].

CONFERENCIA Episcopal Argentina. El Código Civil y nuestro estilo de vida, 2012 [http://www.episcopado.org/portal/actualidad-cea/oficinade-prensa/item/705-el-código-civil-y-nuestro-estilo-de-vida.html fecha de consulta: 3 enero 2017].

CONFERENCIA Episcopal Argentina. La Vida, primer derecho humano, (23 de junio de 2015) [http://episcopado.org/portal/actualidadcea/oficina-de-prensa/item/980-la-vida,-primer-derecho-humanocomisión-ejecutiva,-23-de-junio.html - fecha de consulta: 3 enero 2017].

CONGREGACIÓN para la Doctrina de la Fe, Nota Doctrinal sobre algunas cuestiones relativas al compromiso y la conducta de los católicos en la vida política (24 de noviembre de 2002), 4, Librería Editrice Vaticana, Ciudad del Vaticano 2002

FRANCISCO I. Discurso del Santo Padre a los participantes del congreso internacional "La libertad religiosa según el Derecho Internacional y el Conflicto

Global

$\mathrm{de}$

Valores",

2014 
[[http://w2.vatican.va/content/francesco/es/speeches/2014/june/docum ents/papa-francesco_20140620_liberta-religiosa.html - fecha de consulta: 3 enero 2017].

JUAN Pablo II. Exhortación Apostólica Post-Sinodal Christifideles Laici De Su Santidad Juan Pablo II Sobre Vocación Y Misión De Los Laicos En La Iglesia Y En El Mundo [http://w2.vatican.va/content/john-paulii/es/apost_exhortations/documents/hf_jp-

ii_exh_30121988_christifideles-laici.html - fecha de consulta: 3 enero 2017].

JUAN Pablo II. Carta Encíclica Evangelium Vitae. Valor e inviolabilidad de la vida humana, marzo 1995 [http://www.vatican.va/holy_father/john_paul_ii/encyclicals/documents /hf_jp-ii_enc_25031995_evangelium-vitae_sp. - fecha de consulta: 3 enero 2017]. 